\title{
A PROSPECTIVE, COMPARATIVE STUDY OF TENSION FREE HERNIOPLASTY USING PROLENE HERNIA SYSTEM (PHS) AND LICHTENSTEIN PATCH METHOD (LPM) IN INGUINAL HERNIA
}

\author{
Suchi Gupta1, Pardeep Singh Bhau² \\ ${ }^{1}$ Consultant Surgeon, GMC, Jammu. \\ ${ }^{2}$ Consultant Surgeon, District Hospital, Udhampur.
}

\section{ABSTRACT}

\section{BACKGROUND}

Inguinal hernia repair in men is one of the most common operations in general surgery. Techniques of surgical repair include open suture, open mesh and laparoscopic techniques. Successful hernia surgery involves minimum risk of surgery, anaesthesia, minimum tissue trauma, hospitalization, complications and recurrence. The most effective surgical treatment is unknown. The present study was undertaken to compare the results of tension free hernioplasty using Prolene Hernia System and Lichtenstein Patch Method and to find out the benefits of former over latter if any.

\section{MATERIALS AND METHODS}

This prospective study was conducted on adult male patients admitted in the Surgical Department of Government Medical College, Jammu, for elective surgery of inguinal hernia (Direct/Indirect/Both). Exclusion criteria included age below 18 years, multiple surgical procedures in the groin, recurrent hernia, femoral hernia and strangulated hernia. Twenty-five patients each were randomly distributed to undergo either Prolene Hernia System Repair (PHS) or Lichtenstein Patch Method (LPM). Comparison was performed between the two techniques on basis of duration of surgery, postoperative pain, ambulation, hospital stay, complications and recurrence. Pain was assessed by Visual Analogue Scale (VAS). The data analysed using SPSS.

\section{RESULTS}

Mean time duration in operation on patients using PHS was statistically less as compared to the LMP. Pain scores using Visual Analogue Scale (VAS) were comparable in both the groups. There were only 2 complications in PHS group as compared to 10 in LPM group, the difference being statistically significant. Mean hospital stay was less for PHS group as compared to LPM group, (the difference being statistically significant). There existed no significant difference in terms of return to activity in both the groups. There was no recurrence in the period of follow-up of 6 to 12 months in any patient in both the groups.

\section{CONCLUSION}

Prolene hernia system is a safe and better alternative to traditionally used Lichtenstein hernia "Tension-Free" repair with advantage of less operating time, elimination of recurrence risk, minimal postoperative complications and earlier return to daily activity.

\section{KEYWORDS}

Inguinal Hernia, Prolene Hernia System, Lichtenstein Patch Method, Tension-Free Hernioplasty.

HOW TO CITE THIS ARTICLE: Gupta S, Bhau PS. A prospective, comparative study of tension free hernioplasty using Prolene hernia system (PHS) and Lichtenstein patch method (LPM) in inguinal hernia. J. Evolution Med. Dent. Sci. 2016;5(30):1586-1589, DOI: $10.14260 /$ jemds/2016/373

\section{INTRODUCTION}

Inguinal hernia is a protrusion of a viscus or part of a viscus through an abnormal opening in the wall of cavity containing it. It tends to occur at natural areas of weakness, where muscles are not strong and are vulnerable to intra-abdominal pressure. The term 'Hernia' derives from the Greek word meaning an off shoot, a budding or a bulge. The Latin word 'Hernia' means a rupture or tear.

The risk of inguinal hernia is highest in males and increases with age reaching $22.8 \%$ in persons aged $60-74$ years. The only therapy for inguinal hernia is surgical repair, which is one of the most common performed surgical procedures in the world. It is estimated that worldwide each year over 20 million surgical procedures for inguinal hernias are performed.(1)

Financial or Other, Competing Interest: None.

Submission 08-03-2016, Peer Review 20-03-2016,

Acceptance 23-03-2016, Published 14-04-2016.

Corresponding Author:

Dr. Suchi Gupta,

91/11 Shakti Nagar,

Jammu-180001, Jammu \& Kashmir

E-mail: suchibhau@gmail.com

DOI: $10.14260 /$ jemds $/ 2016 / 373$
Until the 1990s the standard procedure for inguinal hernia repair was represented by the open suture repair with recurrence rates of about $0.8-2.5 \%$ in specialized centres. ${ }^{2}$ ) These acceptable percentages could not be reproduced in general surgery departments where recurrence rates of about $15 \%$ were seen.(3) It is because of these high recurrence rates that the tension free hernia repair with the use of mesh was introduced. The mesh can be placed with either an open or a laparoscopic approach. Since then, a decrease in hernia recurrence is seen to less than $2 \%$ even in non-specialized surgery departments. (4)

Lichtenstein Patch Method (LPM) for tension free inguinal hernia repair is one of the most common procedure, which is used by general surgeons for hernia repair which strengthens the posterior wall by mesh without disturbing the anatomy of inguinal canal.(5)

The most commonly used alternatives to the LPM include both open mesh plug repair, laparoscopic TransAbdominal Pre-Peritoneal Repair (TAPP) and Total ExtraPeritoneal Repair (TEPP), the open pre-peritoneal approach of Nyhus and the open Prolene Hernia System (PHS).(6) The PHS and LPM repairs have shown good outcomes including reduced recurrence, compared with conventional methods. (7) 
These two techniques use different dissection techniques and reinforce different anatomic areas to effect a sound repair. The LPM uses single piece of mesh to overlay and reinforce the transversalis fascia and the posterior wall of the inguinal canal.(8) In contrast, the PHS mesh repair incorporating a one-piece bilobar device connected by a mesh cylinder combines three elements; the mesh covers, the myopectineal orifice and incorporates a circular preperitoneal layer to plug the internal ring with another onlay sheet that covers the posterior wall of the inguinal canal.(9)

The present study was undertaken to compare the results of tension free hernioplasty using PHS and LPM and to find out the benefits of PHS over LPM if any.

\section{MATERIALS AND METHODS}

This prospective, one-year study was conducted on 50 adult ( $\geq 18$ years) male patients admitted in the Surgical Department of Government Medical College, Jammu for elective surgery of inguinal hernia (Direct/Indirect/Both). The study was approved by the Institutional Ethics Committee. Exclusion criteria included age below 18 years, multiple surgical procedures in the groin, recurrent hernia, femoral hernia and strangulated hernia. The diagnosis of hernia was on the basis of history and examination. Informed written consent was obtained from all the patients.

The patients were taken for surgery under Local/Spinal/General/Epidural Anaesthesia. Type of anaesthesia depended on the preoperative assessment of the patient, patient's choice and level of cooperation and availability of anaesthetist.

Twenty-five patients each were randomly distributed to undergo either Prolene Hernia System Repair (PHS) or Lichtenstein Patch Method (LPM), thereby forming two groups of study population. In PHS repair for indirect inguinal hernia, high dissection of neck of hernia was done to create the preperitoneal space. Circular underlay portion of the PHS was folded and inserted through the internal ring and expanded. The onlay patch covered the posterior wall, modified to accommodate the cord structures. The longer end of the onlay patch covered the posterior wall and overlapped the pubic tubercle. The onlay patch was then secured with the clip or suture with pubic tubercle and mid portion of transverses aponeurosis using 3-0 Prolene.

For direct inguinal hernia, defect was circumscribed at its base, the contents were fully reduced and the preperitoneal space was created. The circular underlay portion of the PHS was folded and inserted through the defect allowing the mesh to expand to the underlay position in the floor of the canal. Suture/clips were used to secure the onlay patch in place. Cord was placed in lateral edge of mesh, which was then slit opened and thus a new and strong internal ring was created. The external oblique aponeurosis was then sutured in front of cord, subcutaneous tissue was closed with catgut and skin was closed using silk/skin stapler.

In Lichtenstein Patch Method (LPM), inguinal canal was opened and hernia sac identified. Indirect sac was dissected free and invaginated into the abdomen. In case of large direct hernia, the sac was invaginated by an absorbable imbricating suture to allow positioning of the screen on a flat surface. A sheet of prosthetic mesh measuring $\sim 5 \times 10 \mathrm{~cm}$ was trimmed to fit the area expose and used to reconstruct the entire floor of inguinal canal.
The mesh was then sutured along its lower edge to pubic tubercle, lacunar ligament and to the inguinal ligament beyond the internal ring with a continuous suture of 3-0 Prolene. The superior edge of mesh was then loosely sutured to the rectus sheath and conjoint tendon by same interrupted suture. Cord was placed in lateral edge of mesh, which was then slit opened and thus new and strong ring was created. The external oblique aponeurosis was then sutured in front of cord. Subcutaneous tissue was closed with catgut and skin was closed by using silk/skin stapler.

Antibiotics and analgesics were routinely prescribed to the patients during the postoperative period for varying periods depending upon the requirement of each and every patient. The first dressing in each group was changed on the first postoperative period, thereafter patients were discharged if no sign of any complication was visible. Patients who exhibited signs of complication were advised further stay in the hospital. Postoperatively, the patients were followed up for a period of 6 months.

Comparison was performed between the two techniques on basis of duration of surgery, postoperative pain, ambulation, hospital stay, complications and recurrence. Pain was assessed by Visual Analogue Scale (VAS) and categorized as mild, moderate and severe. The data thus collected was entered in MS Excel for Windows and analysed using SPSS. The continuous variables were presented as average mean and standard deviation, while categorical variable as absolute number and percentage. The parametric data was analysed by 'Student's t-test for unpaired samples, while non-parametric data was analysed using 'chi-square test' or 'Fisher's-exact test,' depending upon the data figure more than or less than 5 respectively. A p-value of $<0.05$ was taken as statistically significant.

\section{RESULTS}

The mean age of the 50 male adult patients was $49 \pm 17.21$ (Range, 20-89) years. Most of the patients were less than 40 years $(38 \%)$, followed by $50-69$ years $(36 \%)$. According to level of activity, $48 \%$ patients were engaged in heavy work followed by $32 \%$ in moderate work, rest led a sedentary lifestyle. Fifteen patients (30\%) had associated diseases, most common being diabetes mellitus $(16 \%)$, ischemic heart disease (6\%), hypertension and chronic obstructive pulmonary disease (4\% each). Right-sided inguinal hernia was present in $54 \%$ patients, left-sided in $38 \%$ and bilateral in $8 \%$ patients. Indirect hernia was diagnosed in $58 \%$, direct type in $38 \%$ and both indirect and direct in $4 \%$ patients.

Type of anaesthesia depended upon the preoperative assessment of the patient, patient's choice and level of cooperation. Maximum number of surgeries were done under spinal anaesthesia (62\%) followed by local (16\%), epidural $(14 \%)$ and general anaesthesia (8\%). Majority of the cases were performed by senior residents $(80 \%)$ and rest $(20 \%)$ by consultants.

Comparison of outcome measures like mean duration of surgery, ambulatory time, postoperative pain scores and mean duration of hospitals stay between PHS and LMP is given in Table 1. Comparison of nature of postoperative complications is given in Table 2. In the present study, statistically there was no significant difference between the two groups in terms of return to work $(p=0.74)$. 
In the PHS group, 70\% patients returned to work within $3^{\text {rd }}$ week and $96 \%$ returned to work within the $5^{\text {th }}$ week, whereas in the LMP group, 55\% patients returned to work within $3^{\text {rd }}$ week and $80 \%$ within the $5^{\text {th }}$ week. All the patients were followed up for a period of six months to one year and no late postoperative complication was found in any of the patients and no recurrence in any patient in both the groups.

\section{DISCUSSION}

Inguinal hernia is the most common problem in our society and so modest improvements in clinical outcome are important. The most important criterion for the selection of method is safety (Morbidity and mortality), recurrence rates and consequence for the patient including the risk of chronic groin pain. In the recent years, great importance has been given to the short-term comfort of the patient, measured by postoperative pain and length of convalescence.(10) The tension-free repair, originally described by Lichtenstein in 1989 , has become the most often used procedure in relation to conventional repairs due to its technical simplicity and low recurrence rates.(11) The use of polypropylene mesh, based on the tension-free concept, is a major breakthrough in the repair of inguinal hernias. The technique developed by Gilbert AI and associates uses the mesh with threedimensional theoretical effect on strengthening and maintaining the posterior wall of the inguinal canal without tension, covering the "Myopectineal orifice."(12)

The use of a three-dimensional mesh (PHS) is intended to include the myofascial defect, enclosing occult femoral or pre-vascular hernias. Its design incorporates a circular preperitoneal layer, a shaft connector, protecting the inner ring with an effect similar to the technique of plug and mesh.(13) and finally a layer above that which is fixed in the posterior wall of the inguinal canal (Transversalis fascia) following the principle of hydrostatic pressure of Pascal, allowing the intra-abdominal pressure to keep the mesh safely in place.(14)

The present study was undertaken to compare the results of the convalescence (Pain and return to normal activity) and long-term sequelae (Chronic pain and recurrence rates) following the inguinal hernia repair using the Lichtenstein's Patch Method (LPM) or prolene hernia system (PHS). The study included 50 male patients in the age group of 20 to 89 years with the mean age of $49.54 \pm 17.21$ years. In the study conducted by Amid et al.(15) all the patients were male in the age group of 20 to 88 years with a mean age of 52 years, which is similar to our study.

In our study indirect hernia was found in $58 \%$ patients, followed by direct hernia in $38 \%$ and bilateral in $4 \%$ patients. Nienhuijs et al.(16) observed indirect hernia in 56\%, direct hernia in $34 \%$ and combined in $10 \%$ of their 334 patients, which is similar to our study. However, unlike Vironen et al.(10) who reported $28 \%$ heavy workers, $56 \%$ moderate and $36 \%$ sedentary workers, our study found that $48 \%$ were heavy workers, $32 \%$ were moderate workers and $20 \%$ were sedentary workers. Similarly, unlike Lichtenstein et al.(17) who encountered right-sided hernia in 33\%, left-sided in $26 \%$ and bilateral in $33 \%$ patients, our study encountered right-sided hernia in 54\%, left sided in $38 \%$ and bilateral in $8 \%$ patients.

In the study conducted by Nienhuijs et al.(16) most of the cases $(77 \%)$ were performed under spinal anaesthesia, which is similar to our study, wherein most of the cases were performed under spinal anaesthesia (62\%).

In our study, mean time duration in operation on patients using PHS (42.4 \pm 8.91 minutes) was statistically $(p=0.0003)$ less as compared to the LMP $(51.4 \pm 7.59$ minutes $)$. The results are similar to other studies. Vironen et al.(10) in their study reported significantly less operating time for PHS procedure (27 minutes) when compared with LPM (37 minutes). Also, Nienhuijs et al.(16) also reported significant shorter mean operating using PHS (42 minutes) when compared with LPM (52 minutes). Kingsnorth et al.(18) reported mean operating time using PHS was shorter (34.1 minutes) as compared to LPM (38.3 minutes), though the difference was statistically not significant.

In the present study, pain experienced was mild in both the groups and pain scores using Visual Analogue Scale (VAS) were comparable in both the groups, which is similar to other studies. $(10,18,19)$ In our study, there were only 2 complications in PHS group as compared to 10 in LPM group. In PHS group, one was wound infection and other was numbness. In LPM group, there were two cases each of seroma and wound infection and one case each of ecchymosis, scrotal swelling and numbness in groin. The difference between the two groups was statistically significant $(p=0.008)$. Similarly, Vironen et al.(10) Chandiramani et al.(19) and Mayagoitia.(20) also reported less number of complications in PHS group as compared to LPM group.

In our study, mean hospital stay was $36.84 \pm 6.51$ hours for PHS group as compared to $42.56 \pm 9.95$ hours for LPM group, the difference being statistically significant $(p=0.02)$. However, there existed no significant $(p>0.74)$ difference in terms of return to activity in both the groups in the present study. Vironen et al.(10) also reported no significant difference in terms of return to work/normal activities in both the groups. Kingsnorth et al.(18) reported that proportions of patients taking longer than 3 days to return to normal activity was $15.5 \%$ in PHS group as compared to $28.4 \%$ with LPM.

In our study, there was no recurrence in the period of follow-up of 6 to 12 months in any patient in both the groups. Nienhuijs et al.(16) reported single recurrence in Lichtenstein's group and no recurrence in PHS group during their follow-up of 12 months. Kingsnorth et al.(18) reported 2 occurrences in the LPM group and no recurrence in PHS group. However, Mayagoitia.(20) reported one recurrence in the PHS group and no recurrence in LPM group.

The operating cost of the Prolene Hernia System is higher than that of Lichtenstein's Patch Method and is a major drawback for its use in the developing countries. However, in our study, the mesh were provided free of cost by the hospital and no patient was asked to purchase it from the market.

\section{CONCLUSION}

Prolene hernia system is a novel approach in the management of the inguinal hernia with encouraging results. It is a safe and better alternative to traditionally used Lichtenstein hernia "tension-free" repair with added advantage of less operating time, elimination of recurrence risk, minimal postoperative complications and earlier return to daily activity, which are important socioeconomic considerations in any day healthcare planning. 


\begin{tabular}{|c|c|c|c|}
\hline $\begin{array}{c}\text { Outcome } \\
\text { Measures }\end{array}$ & PHS & LMP & $\begin{array}{c}\text { p- } \\
\text { value }\end{array}$ \\
\hline $\begin{array}{c}\text { Duration of } \\
\text { surgery in } \\
\text { minutes } \\
\text { (mean } \pm \text { standard } \\
\text { deviation) } \\
\end{array}$ & $42.4 \pm 8.91$ & $51.4 \pm 7.57$ & $0.0003^{*}$ \\
\hline \multicolumn{4}{|c|}{ Ambulatory Time (Hours) } \\
\hline $12-24, \mathrm{n}(\%)$ & $9(36)$ & $3(12)$ & \multirow{3}{*}{$0.003^{*}$} \\
\hline $24-36, \mathrm{n}(\%)$ & $16(64)$ & $14(56)$ & \\
\hline$>36, \mathrm{n}(\%)$ & 0 & $8(32)$ & \\
\hline \multicolumn{4}{|c|}{ First Post-operative Day Pain Score (VAS) } \\
\hline $\begin{array}{l}\text { Mild (1-3), } \\
\text { n (\%) }\end{array}$ & $7(28)$ & $5(20)$ & \multirow{3}{*}{$0.50^{* *}$} \\
\hline $\begin{array}{c}\text { Moderate } \\
(4-6), \mathrm{n}(\%) \\
\end{array}$ & $18(72)$ & $19(76)$ & \\
\hline $\begin{array}{c}\text { Severe }(7-10) \\
\text { n (\%) }\end{array}$ & 0 & $1(4)$ & \\
\hline \multicolumn{4}{|c|}{ First Post-Operative Week Pain Score (Vas) } \\
\hline $\begin{array}{c}\text { Mild (1-3), } \\
\text { n (\%) } \\
\end{array}$ & $20(80)$ & $19(76)$ & \multirow{3}{*}{$0.73^{* *}$} \\
\hline $\begin{array}{c}\text { Moderate }(4-6) \\
n(\%)\end{array}$ & $5(20)$ & $6(24)$ & \\
\hline $\begin{array}{c}\text { Severe }(7-10) \\
n(\%)\end{array}$ & 0 & 0 & \\
\hline $\begin{array}{c}\text { Duration of } \\
\text { hospital stay in } \\
\text { hours } \\
\text { (mean } \pm \text { standard } \\
\text { deviation) }\end{array}$ & $36 \pm 6.51$ & $42.56 \pm 9.95$ & $0.02^{*}$ \\
\hline $\begin{array}{r}\text { Table } \\
\text { Measu }\end{array}$ & Compariso & $\begin{array}{l}\text { fOutcome } \\
\text { Two Groups }\end{array}$ & \\
\hline
\end{tabular}

\begin{tabular}{|c|c|c|}
\hline Complications & PHS, n & LMP, n \\
\hline Numbness in groin & 1 & 4 \\
\hline Seroma & 0 & 2 \\
\hline Wound infection & 1 & 2 \\
\hline Ecchymosis & 0 & 1 \\
\hline Scrotal swelling & 0 & 1 \\
\hline Total complications present & $\mathbf{2}$ & $\mathbf{1 0}$ \\
\hline Absent p = 0.008* \\
\hline Table 2: Nature of Post-operative \\
Complications in Two Groups \\
\hline
\end{tabular}

\section{REFERENCES}

1. Kingsnorth A, Le Blanc K. Hernias: inguinal and incisional. Lancet 2003;362(9395):1561-71.

2. Schumpelick V, Treutner KH, Arlt G. Inguinal hernia repair in adults. Lancet 1994;344(8919):375-9.

3. Beets GL, Oosterhuis KJ, Go PM, et al. Longterm followup (12-15 years) of a randomized controlled trial comparing bassini- stetten, shouldice, and high ligation with narrowing of the internal ring for primary inguinal hernia repair. J Am Coll Surg 1997;185(4):352-7.

4. Nordin P, Bartelmess P, Jansson C, et al. Randomized trial of lichtenstein versus shouldice hernia repair in general surgical practice. Br J Surg 2002;89(1):45-9.
5. Kumar A, Gothwal S, Sharma S, et al. A prospective comparative study of lichtenstein tension free hernioplasty under local anesthesia versus spinal anesthesia. Sch J App Med Sci 2013;1(6):934-6.

6. Sanjay P, Watta DG, Ogstonb SA, et al. Meta-analysis of prolene hernia system mesh versus lichtenstein mesh in open inguinal hernia repair. Surgeon 2012;10(5):283-9.

7. Dalenback J, Andersson C, Anesten B, et al. Prolene hernia system, lichtenstein mesh and plug-and-patch for primary inguinal hernia repair: 3 year outcome of a prospective randomized controlled trial the BOOP study: bi-layer and connector, on-lay, and on-lay with plug for inguinal hernia repair. Hernia 2009;13(2):121-9.

8. Lichtenstein IL, Shulman AG, Amid PK, et al. The tension free hernioplasty. Am J Surg 1989;157(2):188-93.

9. Gilbert AI, Graham MF, Voigt WJ. A bilayer patch device for inguinal hernia repair. Hernia 1999;3(3):161-6.

10. Vironen J, Nieminen J, Eklund A, et al. Randomized clinical trial of lichtenstein patch or prolene hernia system for inguinal hernia repair. Br J Surg 2006;93(1):33-9.

11. Hasegawa S, Yoshikawa T, Yamamoto Y, et al. Long-term outcome after hernia repair with the prolene hernia system. Surg Today 2006;36(12):1058-62.

12. Mottin CC, Ramos RJ, Ramos MJ. Using the prolene hernia system (PHS) for inguinal hernia repair. Rev Col Bras Cir 2011;38(1):024-7.

13. Sanjay P, Harris D, Jones P, et al. Randomized controlled trial comparing prolene hernia system and lichtenstein method for inguinal hernia repair. ANZ J Surg 2006;76(7):548-52.

14. Chauhan A, Tiwari S, Gupta A. Study of efficacy of bilayer mesh device versus conventional polypropelene hernia system in inguinal hernia repair: early results. World J Surg 2007;31(6):1356-9, discussion 1360-1.

15. Amid PK, Shulman AG, Lichtenstein IL. Open tension-free repair of inguinal hernia: the lichtenstein technique. Eur J Surg 1996;162(2):447-53.

16. Nienhuijs S, Kortmann B, Boerma M, et al. Preferred mesh-based inguinal hernia repair in a teaching setting. Arch Surg 2004;139(10):1097-100.

17. Lichtenbstein IL. Herniorraphy a personal experience with 6,321 cases. Am J Surg 1987;153(6):553-9.

18. Kingsnorth AN, Wright D, Porter CS, et al. Prolene hernia system compared with lichtenstein patch: a randomized double blind study of short-term and medium-term outcomes in primary inguinal hernia repair. Hernia 2002;6(3):113-9.

19. Chandiramani VA, Katara AN, Pandya SM. Prolene hernia system in the tension-free repair of primary inguinal hernia. Ind J Surg 2003;65(6):488-91.

20. Mayagoitia JC. Inguinal hernioplasty with prolene hernia system. Hernia 2004;8(1):64-6. 